\title{
Early treatment with, and time receiving, first disease-modifying antirheumatic drug predicts long-term function in patients with inflammatory polyarthritis
}

\author{
Tracey M Farragher, ${ }^{1}$ Mark Lunt, ${ }^{1}$ Bo Fu, ${ }^{1}$ Diane Bunn, ${ }^{2}$ Deborah P M Symmons ${ }^{1}$
}

1arc Epidemiology Unit, Stopford Building, The University of Manchester, Manchester, UK ${ }^{2}$ Norfolk Arthritis Register, Norfolk and Norwich University Hospital, Norwich, UK

\section{Correspondence to}

Professor Deborah Symmons, arc Epidemiology Unit, The University of Manchester, Stopford Building, Oxford Road, Manchester M13 9PT, UK; Deborah.Symmons@ manchester.ac.uk

Accepted 3 October 2009 Published Online First 26 October 2009

\section{ABSTRACT}

Objectives To investigate the influence of early diseasemodifying antirheumatic drug (DMARD) treatment on long-term functional outcome in patients with recentonset inflammatory polyarthritis (IP), and the impact of the duration of first and subsequent DMARD treatment. Methods 642 subjects from a primary care registry of patients with new-onset IP, recruited 1990-4, were followed up for 10 years. Mean change in Health Assessment Questionnaire (HAO) scores between baseline and 10 years were compared by time to, and time receiving, first DMARD treatment and total time receiving treatment, using linear regression. Adjustment for time-dependent confounders and censoring was performed using marginal structural weights.

Results When adjusted for baseline and subsequent disease severity, those treated early $(<6$ months from symptom onset) experienced a non-significant improvement in function compared with those never treated (adjusted mean difference in change (adj_MDIC) in $\mathrm{HAO}-0.24 ; 95 \% \mathrm{Cl}-0.58$ to 0.09 ); and a significant benefit for each additional month of treatment within 6 months of the onset of symptoms (adj MDIC -0.10 ; $95 \% \mathrm{Cl}-0.19$ to -0.02$)$. Patients who discontinued their first DMARD within 6 months experienced a significant deterioration in long-term function (adj MDIC in HAO $0.28 ; 95 \% \mathrm{Cl} 0.04$ to 0.52 ), while those who continued their first treatment for $>3$ years experienced an improvement (adj_MDIC in $\mathrm{HAO}-0.37 ; 95 \% \mathrm{Cl}-0.77$ to 0.04).

Conclusions The importance of time to, and response to, first DMARD treatment and total duration of DMARD treatment in modifying the 10 -year function in patients with IP has been demonstrated.

\section{INTRODUCTION}

A recent systematic review reported that clinical trials have shown the benefit of disease-modifying antirheumatic drugs (DMARDs) and steroids (DMARD/S) in reducing functional disability and disease activity in patients with rheumatoid arthritis (RA). ${ }^{1}$ As highlighted by subsequent commentaries on this review, ${ }^{2-5}$ clinical trials have limitations as most are of short duration (generally $\leq 3$ years) and have narrow patient selection criteria. Longitudinal observational studies (LOS) provide an opportunity to examine the influence of treatment on long-term outcome and are often more generalisable than clinical trials. ${ }^{6}$ However, the effect of treatment is confounded in LOS as those treated most intensively are likely to have the most severe disease. ${ }^{7}$
A number of long-term LOS have examined the influence of DMARDs on outcome in patients with inflammatory polyarthritis (IP) and its subset RA while adjusting for 'confounding by indication'. ${ }^{8-10}$ Choi et al reported a benefit on mortality in 1240 patients with RA treated with methotrexate (MTX), ${ }^{8}$ while we have previously shown that treating patients with IP with DMARD/S, within 6 months of symptom onset, has a beneficial effect on functional disability ${ }^{9}$ and radiological progression ${ }^{10}$ at 5 years. Our analyses adjusted for the decision to prescribe the first DMARD but not for subsequent treatment decisions. Over time, particularly in the long-term, potential confounders will alter, both as a result of the natural course of the disease and also in response to treatment. Therefore, to assess the impact of treatment over the long term, adjustment for these time-dependent confounders is required.

In addition to the influence of the timing of the first treatment, time receiving the first treatment and total duration of treatment may also contribute to subsequent long-term outcome. A Swedish trial of 245 patients with recent-onset RA found that those who received their first DMARD treatment for $<2$ years had lower response and remission rates than those who continued with treatment. ${ }^{11}$ Analysis of 2888 patients with established RA from the ARAMIS database, found that the consistent use of a DMARD (measured as the proportion of visits at which a patient was taking at least one DMARD) was associated with improved functional outcome. ${ }^{12}$

Our study was conducted in an inception cohort of patients with IP followed up for 10 years with regular assessment of disease activity, physical function and treatment. We have adjusted for potential time-dependent confounders over the length of the follow-up. We aimed to investigate whether the benefit of early DMARD treatment on functional outcome continues in the long term and to examine the impact of the duration of first and subsequent DMARD treatment.

\section{PATIENTS AND METHODS \\ Patients}

Patients were recruited from the Norfolk Arthritis Register (NOAR), a primary care-based inception cohort of subjects with recent-onset IP. As described in detail elsewhere, ${ }^{13}$ NOAR aims to recruit all adults aged $\geq 16$ years, who have swelling of at least two joints persisting for at least 4 weeks and whose symptom onset was after 1 January 1990. The catchment area is the former 
Norwich Health Authority, with notification of cases through general practitioners or attendance at hospitals. Those who were subsequently diagnosed by a hospital consultant as having a condition other than RA, IP, psoriatic arthritis or postviral arthritis were excluded. Between 1990 and 1994, 1098 subjects were registered with NOAR who satisfied the above criteria. Fourteen subjects were excluded as they had begun DMARD or steroid treatment for another condition before the onset of IP symptoms, leaving 1084 subjects.

\section{Data collection}

\section{Baseline}

Clinical and demographic data were collected by a research nurse by a structured interview and clinical examination shortly after registration (baseline) as outlined in table 1. Detailed information was collected on the use of DMARDs and steroids (DMARD/S) and hospital attendance for patient with IP. Each subject completed the Health Assessment Questionnaire (HAQ), modified for use in British patients. ${ }^{14}$

A blood sample was taken for rheumatoid factor (RF), anticyclic citrullinated peptide antibody and C-reactive protein (CRP) testing. The Disease Activity Score (DAS28) was calculated from the 28 tender joint count, 28 swollen joint count and CRP (http://www.das-score.nl/www.das-score.nl/index.html, accessed 14 January 2010). Human leucocyte antigen (HLA) genotyping was performed as described previously. ${ }^{15}$ Subtyping at the HLA-DRB1 locus was performed to identify the presence of the shared epitope.

\section{Follow-up}

Annual assessments were carried out for 3 years, then at fifth, seventh and tenth years. Dates of starting and stopping any DMARD treatment since the last assessment were recorded as well as the reasons for stopping (eg, inefficacy, adverse events). Blood was taken for RF testing at the first and second annual assessment if the subject had been RF negative previously. A blood sample was taken from all subjects at the fifth and tenth assessments for RF and CRP testing. The American College of Rheumatology (ACR) 1987 classification criteria for RA were applied both cross-sectionally at baseline and cumulatively at each assessment, as described previously. ${ }^{16}$

Patients attended for x-ray examinations of their hands and feet at the first and/or second assessment, if they had already satisfied the ACR criteria for RA or if the presence of erosions would lead to the patient satisfying them. All patients were invited to have x-ray examinations at the fifth assessment and only those who were erosive at the fifth were invited to the tenth assessment. Radiographs were scored using the Larsen method $^{17}$ by two rheumatologists, and major disagreements were arbitrated by a third. ${ }^{18}$ Patients completed the Medical

Table 1 Variables used in the marginal structural weight models

\begin{tabular}{|c|c|}
\hline Variable & Variable type \\
\hline \multicolumn{2}{|l|}{ Demographics } \\
\hline Age at symptom onset and at each assessment & Decades \\
\hline Gender & Male/Female \\
\hline $\begin{array}{l}\text { Months from symptom onset at baseline and at each } \\
\text { assessment }\end{array}$ & Tertiles by assessment \\
\hline Smoking status at each assessment & $\begin{array}{l}\text { Never smoked/Stopped } \geq 10 \text { years before assessment// } \\
\text { Stopped }<10 \text { years before assessment/Current smoker }\end{array}$ \\
\hline \multicolumn{2}{|l|}{ Serological and genetic } \\
\hline Anti-CCP status at baseline (Axis-Shield DIASTAT kit) & $<5 \mathrm{U} / \mathrm{ml} / \geq 5 \mathrm{U} / \mathrm{ml}$ \\
\hline $\begin{array}{l}\text { CRP category at baseline and assessment (end point } \\
\text { immunoturbidimetric agglutination) }\end{array}$ & $\leq 10 \mathrm{mg} / \mathrm{l} />10 \mathrm{mg} / \mathrm{l}$ \\
\hline $\begin{array}{l}\text { RF status at baseline and by assessment (latex } \\
\text { agglutination) }\end{array}$ & $<1: 40 / \geq 1: 40$ \\
\hline Number of copies of the SE & $0 / 1 / 2$ \\
\hline Homozygous for SE & No/Yes \\
\hline \multicolumn{2}{|l|}{ Disease activity and severity } \\
\hline \multicolumn{2}{|l|}{ DAS28 score at baseline and assessment } \\
\hline $\begin{array}{l}\text { ACR criteria for RA cross-sectional at baseline and } \\
\text { cumulative at assessment }\end{array}$ & Not met/Met \\
\hline $\begin{array}{l}\text { Number of swollen, tender and (both tender and swollen) } \\
\text { joints at baseline and assessment }\end{array}$ & Tertiles by assessment \\
\hline Presence of nodules at baseline and assessment & No/Yes \\
\hline $\mathrm{HAO}$ group at baseline and assessment & $<1 / \geq 1$ to $<2 / \geq 2$ \\
\hline Presence of erosions by assessment & No/Yes \\
\hline Larsen score by assessment & Tertiles by assessment \\
\hline \multicolumn{2}{|l|}{ Physical Component Score (PCS) of SF36 } \\
\hline \multicolumn{2}{|l|}{ Mental Component Score (MCS) of SF36 } \\
\hline $\begin{array}{l}\text { Diagnosed with any of } 14 \text { defined comorbidities by } \\
\text { assessment }\end{array}$ & No/Yes \\
\hline \multicolumn{2}{|l|}{ Treatment and hospital attendance } \\
\hline Attended/referred to hospital since last assessment & No/Yes \\
\hline $\begin{array}{l}\text { Treated with SSZ, MTX, other DMARDs and steroids at } \\
\text { baseline and by assessment }\end{array}$ & No/Yes \\
\hline $\begin{array}{l}\text { Ceased treatment since last assessment or } \\
\text { by assessment due to inefficacy or adverse event }\end{array}$ & No/Yes \\
\hline Remission by baseline and assessment & No/Yes \\
\hline
\end{tabular}


Outcomes Study Short Form-36 (SF-36) (a validated generic health status measure), ${ }^{19}$ at the third and/or fifth years. ${ }^{20}$

\section{Statistical analysis}

Treatment history

All analysis was conducted using Stata version 9.2 (StataCorp, College Station, Texas, USA). The time from symptom onset to the date of the first treatment was categorised into three groups ( $<6$ months, $6-12$ months and $>12$ months). The duration of the first DMARD/S treatment and total duration of treatment over the 10 years of follow-up, taking into account combination therapies, were divided into tertiles (first DMARD/S treatment $\leq 6$ months, $>6$ to $\leq 36$ months and $>36$ months; total duration $\leq 48$ months, $>48$ to $\leq 96$ months, $>96$ months).

\section{Outcome by 10 years and treatment}

The change in HAQ score between baseline and the 10-year follow-up was included in a linear regression model, adjusted by baseline $\mathrm{HAO}$, in order to estimate the effect on long-term functional disability of treatment, as well as the time to, and time receiving, the first treatment, and total time receiving treatment. Patients who had never received DMARD/S were used as the referent group. To explore the effect of the interaction between time to, and time receiving, treatment the duration of the first and any DMARD/S treatment, including combination therapies, were stratified into the number of months of treatment in the first 6 months since symptom onset, and the number of months of treatment after the first 6 months since symptom onset.

\section{Marginal structural models}

We have previously adjusted for 'confounding by indication' using propensity scores. ${ }^{9}{ }^{10}$ However, while this method adjusted for initiation of first DMARD/S, no adjustment was made for subsequent treatment decisions. On this occasion, we used marginal structural models to adjust for time-dependent confounders, such as the HAQ. ${ }^{81}$ At each follow-up, a logistic regression model was used to estimate the probability that the patient was receiving the observed treatment. Baseline, previous and assessment-specific variables were used in the model to predict the treatment decisions as outlined in table 1. This method aims to include as many potential predictors as possible, even if their contribution is small. The reciprocal of the probability was used if the patient was not receiving treatment at that assessment. The product of all the probabilities for each patient gave the overall probability of the treatment decisions that occurred over the length of follow-up. The inverse of this probability (the inverse-probability-of-treatment weight) was then used to adjust each patient's change in HAO for the varying treatments and time-dependent confounders. However, without a numerator this inverse weight is likely to be highly variable and so the inverse-probability-of-treatment weight is stabilised..$^{21}$ The numerator was the product over the length of the follow-up of the proportions of patients receiving treatment at each assessment.

To allow for loss to follow-up, a stabilised inverse-probabilityof-censoring weight was calculated, based on the same methods outlined above. Without adjustment for loss to follow-up, any estimate of the change in $\mathrm{HAO}$ in the tenth assessment completers would be biased. At each assessment, the probability of the subject still being in NOAR by the next assessment was estimated using a logistic regression model with the same variables as in the treatment decision model. The inverse product of these probabilities was also stabilised and this censoring weight was multiplied by the stabilised inverse-probability-of-treatment weight to provide a weight that produced a pseudo population by the tenth assessment, in which both treatment and loss to follow-up are independent of any of the variables considered to be potential time-varying confounders, enabling an unbiased estimate of the effect of treatment.

The logistic regression models can only include patients with complete data. In total, 162840 data items were included in the models used to produce the weights. Of these, 6785 (4.2\%) were missing. To impute missing data we used switching regression, an iterative multivariable regression technique which retains an element of random variation in the estimates. ${ }^{22}$ Within Stata these methods are incorporated within the ice and uvis programs. For each variable the distributions were compared with and without the imputed data to confirm that the imputed data did not alter the distribution of any of the variables. The imputed data were only used in the prediction of treatment decisions and loss to follow-up, and were not included in the change in $\mathrm{HAO}$ models as the marginal structural model accounts for loss to follow-up as well as time-dependent confounders.

\section{RESULTS \\ Cohort characteristics and treatment over 10 years of follow-up}

The median age at symptom onset of the 1084 subjects was 53 years (IOR 41-66) with two-thirds being women (table 2). At the baseline assessment, 493 (45.5\%) subjects satisfied the 1987 ACR criteria for RA. After 10 years, 664 (61.3\%) subjects continued to be followed up.

There was an increasing use of MTX, a decreasing use of sulfasalazine (SSZ) and a stable use of steroids with time (table 3). At baseline, $7 \%$ of subjects receiving a DMARD/S were receiving MTX and $60 \%$ SSZ. At the tenth year assessment, $54 \%$ were receiving MTX and $37 \%$ SSZ. This reflects the changing management of RA during the 1990s. When restricted to those subjects who satisfied the ACR criteria for RA by 10 years, the proportion treated was higher (eg, $64 \%$ ever treated by 10 years) but the pattern of the types of treatment was the same (data not shown).

\section{HAO score at baseline, 10 years and difference over 10 years by time to, and time receiving, treatment}

Of the 664 subjects with 10 years of follow-up, 642 subjects had completed a HAQ both at baseline and the 10-year assessment; $54 \%$ of these had been treated by 10 years, of whom $35 \%$ were treated within 6 months of symptom onset (table 4). As expected patients who were judged not to require DMARD/S treatment by the tenth assessment had milder disease with lower baseline $\mathrm{HAO}$ scores and smaller mean change in $\mathrm{HAO}$ over the follow-up period $(0.13,95 \%$ CI 0.05 to 0.21$)$ than those who were treated. The patients with the highest baseline HAO were most likely to receive early treatment, but had no mean change in $\mathrm{HAQ}$ over the 10 years $(0.00,95 \% \mathrm{CI}-0.17$ to 0.17$)$. Those who continued to receive their first DMARD the longest, experienced the least deterioration in HAQ over the follow-up period. Patients who continued to receive their first DMARD/S for 3 years or more experienced a deterioration in $\mathrm{HAQ}$ of only half $(0.16,95 \%$ CI 0.002 to 0.32$)$ that seen in patients who stopped their first DMARD within 6 months of starting it $(0.35$, $95 \%$ CI 0.15 to 0.55$)$.

After an initial improvement in the first year of follow-up, all groups showed a steady decline in functional disability over the 10 years (figure 1). Patients who were receiving DMARD/S treatment at each follow-up reported poorer function than those 
patients not receiving treatment, highlighting the fact that treatment was more likely to be given to patients with more severe disease.

\section{Change in $\mathrm{HAQ}$ over 10 years and treatment, with adjustment by time-dependent confounders}

When adjusted for baseline HAQ only, those ever treated with $\mathrm{DMARD} / \mathrm{S}$ had a significantly greater deterioration in function over 10 years, than those never treated (adjusted mean difference in change (adj_MDIC) in HAQ $0.30,95 \%$ CI 0.18 to 0.42 )

Table 2 Baseline characteristics of the cohort

\begin{tabular}{|c|c|}
\hline Baseline characteristics & $\begin{array}{l}\text { IP cohort } \\
(n=1084)\end{array}$ \\
\hline Age at symptom onset (years), median (IQR) & $53(41-66)$ \\
\hline Female, $\mathrm{n}(\%)$ & $709(65.4)$ \\
\hline Symptom duration at registration (months), median (IOR) & $4(2-10)$ \\
\hline HAQ score, median (IOR)* & $0.75(0.25-1.375)$ \\
\hline $\mathrm{CRP}(\mathrm{mg} / \mathrm{d} \mathrm{l})$, median $(\mathrm{IQR})^{\dagger}$ & $5(0-16)$ \\
\hline DAS28 score, median $(I O R)^{\dagger}$ & $3.93(2.89-5.01)$ \\
\hline Swollen joint count, median (IQR) & $6(2-13)$ \\
\hline Tender joint count, median (IQR) & $7(3-16)$ \\
\hline Swollen and tender joint count, median (IOR) & $3(0-8)$ \\
\hline Satisfied 1987 ACR criteria for RA, $n(\%)$ & $493(45.5)$ \\
\hline Presence of nodules, $n(\%)$ & $72(6.6)$ \\
\hline \multicolumn{2}{|l|}{ Smoking status at baseline, $\mathrm{n}(\%)$} \\
\hline Never smoked & $353(32.6)$ \\
\hline Ex-smoker $\geq 10$ years & $282(26)$ \\
\hline Ex-smoker $<10$ years & $161(14.9)$ \\
\hline Current smoker & $288(26.6)$ \\
\hline
\end{tabular}

*HAO completed by 1072 subjects: ${ }^{\dagger}$ CRP measured on 866 subjects.

ACR, American College of Rheumatology; CRP, C-reactive protein; DAS28, 28 joint count Disease Activity Score; HAQ, Health Assessment Questionnaire; IP, inflammatory

polyarthritis; RA, rheumatoid arthritis. (table 5). However, after adjustment for the time-dependent confounders there was no significant difference in the change in $\mathrm{HAQ}$ between those ever treated and those not treated $(-0.01$, $95 \%$ CI -0.20 to 0.19$)$. In other words, after allowing for the fact that treatment is more likely to be given to those with severe and active IP, treatment has been shown to move patients onto a trajectory that they would have followed if they had had milder disease not requiring treatment. On adjustment those treated early ( $<6$ months) experienced an improvement in functional disability over the 10 years $(-0.24,95 \%$ CI -0.58 to 0.09$)$, although this was not significant.

Of the 345 subjects treated over the 10 years, 290 (84\%) were no longer receiving their first treatment by 10 years of follow-up. Patients who discontinued their first treatment (either stopped, change or added another DMARD/S) within 6 months of starting, experienced a significant deterioration in functional disability (adj_MDIC $0.28,95 \%$ CI 0.04 to 0.52 ); those who continued to receive their first treatment for $>36$ months experienced an

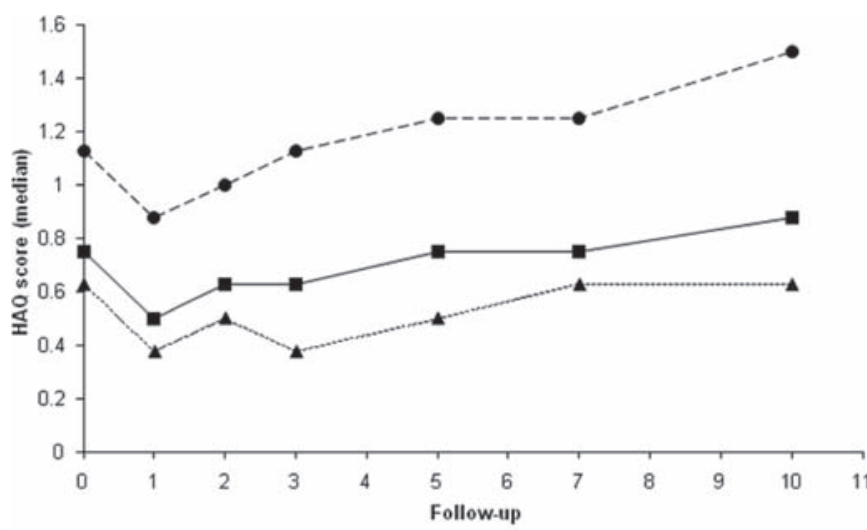

$\rightarrow-I P \quad-\bullet-$ On treatment at follow-up $\cdots \star \cdots$ Not on treatment at follow-up

Figure 1 No adjustment for confounders may lead to the incorrect inference that those patients who were receiving disease-modifying antirheumatic drug treatment at each follow-up experienced poorer function, compared with those patients not receiving treatment. $\mathrm{HAO}$, Health Assessment Questionnaire; IP, inflammatory polyarthritis.

Table 3 Disease-modifying antirheumatic drug (DMARD)/steroid treatment received over 10 years of follow-up

\begin{tabular}{|c|c|c|c|c|c|c|}
\hline \multirow[b]{2}{*}{ Year of follow-up } & \multirow[b]{2}{*}{ Cohort (n) } & \multirow{2}{*}{$\begin{array}{l}\text { Treated between previous and current } \\
\text { follow-up, } \mathbf{n}(\%)\end{array}$} & \multicolumn{4}{|c|}{ DMARD/steroid treatment between previous and current follow-up, n (\%) } \\
\hline & & & Sulfasalazine (SSZ) & Methotrexate (MTX) & Steroid (Ss) & Other \\
\hline $0^{*}$ & 1084 & $226(21)$ & $135(60)$ & $15(7)$ & $72(32)$ & $17(8)$ \\
\hline 1 & 1025 & $450(44)$ & $283(63)$ & $69(15)$ & $139(31)$ & $36(8)$ \\
\hline 2 & 961 & $418(43)$ & $225(54)$ & $91(22)$ & $128(31)$ & $40(10)$ \\
\hline 3 & 924 & $396(43)$ & $194(49)$ & $114(29)$ & $124(31)$ & $38(10)$ \\
\hline 5 & 855 & $374(44)$ & $164(44)$ & $144(39)$ & $127(34)$ & $32(9)$ \\
\hline 7 & 732 & $305(42)$ & $113(37)$ & $150(49)$ & $98(32)$ & $25(8)$ \\
\hline \multirow[t]{2}{*}{10} & 664 & $293(44)$ & $108(37)$ & $159(54)$ & $95(32)$ & $22(8)$ \\
\hline & & & \multicolumn{4}{|c|}{ Ever DMARD/steroid treatment by follow-up, n (\%) } \\
\hline Year of follow-up & Cohort (n) & Ever treated by follow-up, $n(\%)$ & Sulfasalazine (SSZ) & Methotrexate (MTX) & Steroid (Ss) & Other \\
\hline 0 & 1084 & $226(21)$ & $135(60)$ & $15(7)$ & $72(32)$ & $17(8)$ \\
\hline 1 & 1025 & $453(44)$ & $285(63)$ & $70(15)$ & $139(31)$ & $41(9)$ \\
\hline 2 & 961 & $464(48)$ & $298(64)$ & $101(22)$ & $151(33)$ & $56(12)$ \\
\hline 3 & 924 & $466(50)$ & $308(66)$ & $134(29)$ & $156(33)$ & $60(13)$ \\
\hline 5 & 855 & $444(52)$ & $294(66)$ & $170(38)$ & $161(36)$ & $64(14)$ \\
\hline 7 & 732 & $374(51)$ & $255(68)$ & $182(49)$ & $142(38)$ & $58(16)$ \\
\hline 10 & 664 & $361(54)$ & $255(71)$ & $192(53)$ & 142 (39) & $62(17)$ \\
\hline
\end{tabular}

*Treated since symptom onset to baseline. 
Table 4 Health Assessment Questionnaire (HAO) at baseline, 10 years and difference over 10 years, by time to, and time receiving, treatment

\begin{tabular}{|c|c|c|c|c|}
\hline & n (\%) & $\begin{array}{l}\text { Baseline HAO } \\
\text { Median (IOR) }\end{array}$ & $\begin{array}{l}10 \text { Year HAO } \\
\text { Median (IOR) }\end{array}$ & $\begin{array}{l}\text { Change over } 10 \\
\text { years } \\
\text { Mean (95\% CI) }\end{array}$ \\
\hline $\begin{array}{l}\text { Not treated over } \\
\text { follow-up }\end{array}$ & $297(46)$ & $0.50(0.13-0.88)$ & $0.50(0.13-1.25)$ & $0.13(0.05$ to 0.21$)$ \\
\hline Treated over follow-up & $345(54)$ & $1.00(0.50-1.50)$ & $1.38(0.50-2.00)$ & 0.24 (0.14 to 0.33$)$ \\
\hline \multicolumn{5}{|l|}{ Time to first treatment } \\
\hline$<6$ Months & $122(35)$ & $1.25(0.63-1.75)$ & $1.25(0.25-2.13)$ & $0.00(-0.17$ to 0.17$)$ \\
\hline 6-12 Months & $76(22)$ & $1.00(0.44-1.63)$ & $1.50(0.50-2.00)$ & $0.28(0.08$ to 0.48$)$ \\
\hline$>12$ Months & $147(43)$ & $0.75(0.38-1.38)$ & $1.38(0.63-2.00)$ & 0.41 (0.28 to 0.54$)$ \\
\hline \multicolumn{5}{|c|}{ Time receiving first treatment } \\
\hline $\begin{array}{l}\leq 6 \text { Months } \\
>6 \text { to } \leq 36 \text { Months }\end{array}$ & $\begin{array}{r}91(26) \\
123(36)\end{array}$ & $\begin{array}{l}1.00(0.38-1.50) \\
1.00(0.38-1.63)\end{array}$ & $\begin{array}{l}1.63(0.50-2.13) \\
1.38(0.63-2.00)\end{array}$ & $\begin{array}{l}0.35(0.15 \text { to } 0.55) \\
0.24(0.10 \text { to } 0.38)\end{array}$ \\
\hline$>36$ Months & $131(38)$ & $0.88(0.50-1.50)$ & $1.25(0.25-1.88)$ & $0.16(0.002$ to 0.32$)$ \\
\hline \multicolumn{5}{|c|}{ Time receiving any treatment over 10 years } \\
\hline $\begin{array}{l}\leq 48 \text { Months } \\
>48 \text { to } \leq 96 \text { Months }\end{array}$ & $\begin{array}{l}88(26) \\
57(17)\end{array}$ & $\begin{array}{l}0.88(0.25-1.50) \\
0.88(0.38-1.63)\end{array}$ & $\begin{array}{l}0.88(0.06-1.63) \\
1.50(0.63-2.00)\end{array}$ & $\begin{array}{l}0.06(-0.12 \text { to } 0.25) \\
0.38(0.13 \text { to } 0.63)\end{array}$ \\
\hline$>96$ Months & $200(58)$ & $1.00(0.50-1.56)$ & $1.50(0.63-2.13)$ & $0.27(0.15$ to 0.39$)$ \\
\hline
\end{tabular}

Table 5 Mean difference in change in Health Assessment Questionnaire (HAO) over 10 years by time to, and time receiving, treatment—adjusted by baseline $\mathrm{HAO}$ and marginal structural weight

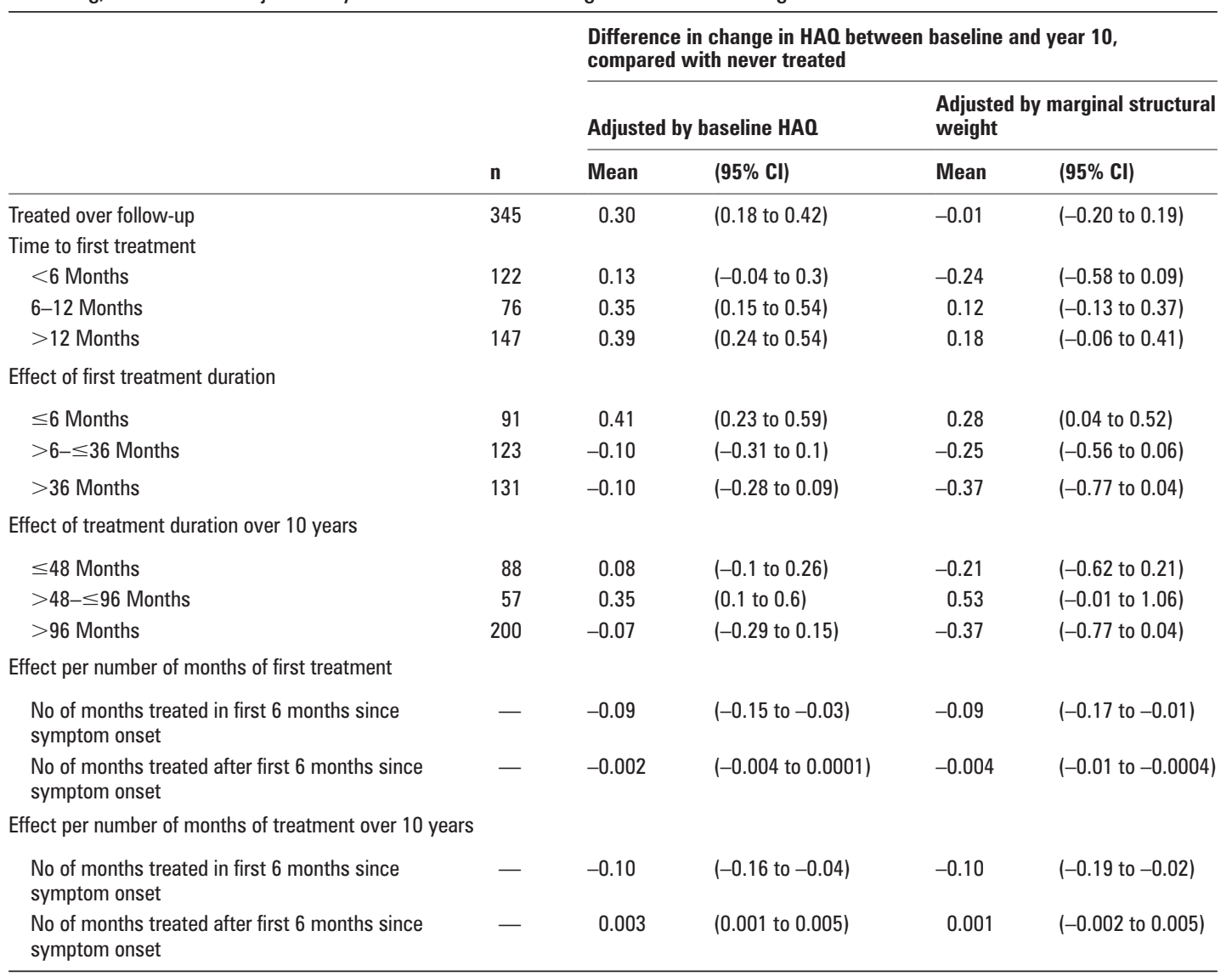

improvement (adj_MDIC $-0.37,95 \%$ CI -0.77 to 0.04 ), although this was not significant.

Of the 642 subjects who had completed a HAQ both at baseline and at the 10 year assessment, 497 (77.4\%) satisfied the ACR criteria for RA cumulatively over the 10 years of follow-up. Of these subjects, 316 (64\%) had been treated by 10 years, of whom $110(35 \%)$ were treated within 6 months of symptom onset. The results in table 5 were very similar when confined to those who satisfied the ACR criteria for RA cumulatively over the 10 years of follow-up (data not shown).

The impact of early treatment on long-term functional disability is further highlighted by the significant benefit from each additional month of early treatment, be that the first DMARD/S (adj_MDIC $-0.09,95 \%$ CI -0.17 to -0.01 ) or any subsequent 
treatment within the first 6 months of symptoms (adj_MDIC $-0.10,95 \% \mathrm{CI}-0.19$ to -0.02$)$. Furthermore, a significant benefit from each additional month of the continuation of the first treatment past 6 months was found (adj_MDIC -0.004, 95\% CI -0.01 to -0.0004$)$.

\section{DISCUSSION}

The results of this analysis have three important clinical messages. The first is that the benefits of early DMARD/S treatment in patients with IP are still apparent after 10 years of follow-up. Even in the unadjusted analysis, those who started their first DMARD/S within 6 months of symptom onset had no overall deterioration in $\mathrm{HAQ}$, whereas those who started treatment later experienced deterioration. When adjusted for baseline disease severity and subsequent treatment decisions, those treated early experienced a non-significant improvement in change in function compared with those judged by their clinicians not to require DMARD/S at all (adj_MDIC in $\mathrm{HAO}-0.24,95 \% \mathrm{CI}-0.58$ to 0.09 ); and a significant benefit from each additional month of treatment within 6 months of the onset of symptoms (adj_MDIC -0.10, 95\% CI -0.19 to -0.02$)$. This provides still further evidence of a 'window of opportunity' for optimal benefit from the introduction of DMARD/S and that early referral to a rheumatologist is justified. ${ }^{23}$

We have previously reported the benefit of early treatment with respect to physical function at 5 years in the NOAR cohort. ${ }^{9}$ In that analysis we used the propensity score method to adjust for baseline disease activity and thus confounding by indication. This showed the benefit of early treatment regardless of subsequent treatment duration. In this new analysis we test the hypothesis that the time receiving first treatment is also an important prognostic indicator. We found that patients who discontinued their first DMARD/S within 6 months experienced a significant deterioration in long-term functional ability, irrespective of subsequent treatment decisions (adj_MDIC in $\mathrm{HAQ}$ $0.28,95 \%$ CI 0.04 to 0.52 ). This has important implications for the future treatment of patients with IP. For example, presently in the UK, anti-tumour necrosis factor treatment is only recommended for patients for whom two or more DMARD/S have failed. ${ }^{24}$ Our results suggest that patients who fail to respond to, or cannot tolerate, their first DMARD/S are likely to have a poor long-term outcome and that it may be appropriate to consider more aggressive treatment at this stage rather than wait for another DMARD/S to fail.

The third clinical message is that the total duration of DMARD/S over the first 10 years of disease has an important impact on functional outcome. Patients who received a total duration of treatment $>8$ years experienced an improvement in function compared with those never treated (adj_MDIC in HAQ $-0.37 ; 95 \%$ CI -0.77 to 0.04 ). Other studies have also shown that the benefit of early treatment is not sustained unless that treatment is continued. For example, a randomised controlled trial in the Netherlands found clinical and radiological benefit at 12 months in those randomised to early aggressive treatment compared with the pyramid approach. ${ }^{25}$ However, in the 5-year follow-up of this cohort these differences did not persist. ${ }^{26}$ As the treatment strategies were not continued during follow-up, the authors conclude that early aggressive treatment should be continued into the long term.

Inevitably, a 10-year follow-up study reflects the changing prescribing practice over the period of follow-up. Patients in this study were recruited in the early 1990s when SSZ monotherapy was the usual first DMARD. However, even though the treatment strategies in the 1990s were less aggressive than those used today, we were still able to show a benefit of early and sustained treatment. It is likely that the benefit will be greater with the use of MTX and combination therapy much earlier in the disease course.

Until recently there were relatively few treatment options for patient with IP and RA and treatment goals were less ambitious than they are now. Therefore clinicians continued to prescribe a treatment even if there was only minor improvement so long as no adverse events were seen. Many studies looked at drug survival rates as an outcome in itself, ${ }^{27-29}$ rather than the subsequent consequences of treatment persistence on patient outcomes, as we have done here. The current strategy of targeting remission or low-disease activity results in the faster changing of DMARDs and so shortening of times on any particular treatment. Thus, the association between the time receiving the first treatment and functional disability may be stronger in patients presenting now. A pooled analysis of MTX and anti-anti-tumour necrosis factor clinical trials of patients with early RA found that disease activity at baseline and particularly at 3 months (ie, early treatment response) was significantly related to disease activity after 1 year. ${ }^{30}$ We would have liked to have explored the consequences of treatment strategies on radiological progression. We have previously shown that treating patients within 6 months of IP symptom onset has a beneficial effect on radiological progression $^{10}$ at 5 years. However x-ray examinations were not undertaken on all subjects at the tenth assessment, therefore radiological progression by 10 years' follow-up could not be analysed.

Our study has a number of strengths and weaknesses. It uses a primary care-based inception cohort of patients followed up systematically over a 10-year period. Patients were recruited with IP rather than RA. We have therefore been able to include patients who do not satisfy the ACR criteria for RA at baseline but do satisfy them subsequently. The results should therefore have good generalisability. Some rheumatologists might consider the inclusion of subjects with RA, IP, psoriatic arthritis or postviral arthritis as patients with different disease course and treatment strategies. However, the marginal structural models approach adjusts for the differences in disease severity and treatment over time which might be seen in the different conditions. Furthermore, the restriction in the analysis in table 4 to those 497 patients (77\% of those who had 10 year follow-up) who cumulatively satisfied the ACR criteria for RA, produced results similar to that for the whole IP cohort.

Adjusting for a series of treatment decisions and fluctuating disease activity over 10 years is complex, particularly as patients were seen at predefined time intervals and not specifically at the time of flares or treatment change. A variety of methods have been suggested including propensity scores, ${ }^{31}$ as we have used previously. ${ }^{9}{ }^{10}$ In this study, we used marginal structural models as they are the only method which adjusts for time-varying confounders. This method has only been used previously once in RA research. ${ }^{8}$ There is a debate as to which variables should be included in the models. ${ }^{32}$ In accordance with the recommendations of Rubin ${ }^{33}$ and Robins et $a^{\beta 4}$ we included variables even with weak effects on outcome (although strong associations with treatment) in order to minimise bias. Results from simulation experiments ${ }^{32}$ suggest that variables related to outcome but not to treatment should always be included as they decrease the variance of estimates without increasing bias. However, the possibility of residual confounding remains owing to unmeasured variables that are associated either with treatment decisions or with outcome. While we included variables that cover the full 
spectrum of disease activity, previous treatment and comorbidity, unmeasured confounders might include patient preferences and compliance.

In summary we have demonstrated the importance of time to first DMARD/S treatment, response to first DMARD/S and total duration of DMARD treatment over a 10-year time period in patients with early IP using state-of-the-art statistical methods to adjust for time varying confounding.

Acknowledgements We are grateful to the general practitioners and rheumatologist in the Norwich area for their continuing support of NOAR and acknowledge the contribution of the NOAR metrologists in the collection of the clinical data, and database manager Stephanie Manning.

Funding All work was funded by the Arthritis Research Campaign, UK, arc grant reference no: 17552

Competing interests None.

Ethics approval This study was conducted with the approval of the Norwich Research Ethics Committee.

Provenance and peer review Not commissioned; externally peer reviewed.

\section{REFERENCES}

1. Donahue KE, Gartlehner G, Jonas DE, et al. Systematic review: comparative effectiveness and harms of disease-modifying medications for rheumatoid arthritis. Ann Intern Med 2008;148:124-34.

2. Boers M. A call for pragmatic treatment trials in rheumatoid arthritis. Nat Clin Pract Rheumatol 2008;4:292-3.

3. Pincus T, Yazici Y, Sokka T. Are excellent systematic reviews of clinical trials useful for patient care? Nat Clin Pract Rheumatol 2008;4:294-5.

4. Smolen JS, Aletaha D. Strengths and limitations of a systematic review on DMARDs for rheumatoid arthritis. Nat Clin Pract Rheumatol 2008;4:296-7.

5. Weisman MH. Do all drugs and treatments for rheumatoid arthritis have the same efficacy? Nat Clin Pract Rheumatol 2008;4:298-9.

6. Pincus T, Sokka T. Clinical trials in rheumatic diseases: designs and limitations. Rheum Dis Clin North Am 2004;30:701-24, v-vi.

7. Landewe RBM. The benefits of early treatment in rheumatoid arthritis: confounding by indication, and the issue of timing. Arthritis Rheum 2003;48:1-5

8. Choi HK, Hernán MA, Seeger JD, et al. Methotrexate and mortality in patients with rheumatoid arthritis: a prospective study. Lancet 2002;359:1173-7.

9. Wiles NJ, Lunt M, Barrett EM, et al. Reduced disability at five years with early treatment of inflammatory polyarthritis: results from a large observational cohort, using propensity models to adjust for disease severity. Arthritis Rheum 2001;44:1033-42.

10. Bukhari MA, Wiles NJ, Lunt M, et al. Influence of disease-modifying therapy on radiographic outcome in inflammatory polyarthritis at five years: results from a large observational inception study. Arthritis Rheum 2003;48:46-53

11. Svensson B, Ahlmén M, Forslind K. Treatment of early RA in clinical practice: a comparative study of two different DMARD/corticosteroid options. Clin Exp Rheumatol 2003:21:327-32.

12. Fries JF, Williams CA, Morfeld D, et al. Reduction in long-term disability in patients with rheumatoid arthritis by disease-modifying antirheumatic drug-based treatment strategies. Arthritis Rheum 1996;39:616-22.

13. Symmons DP, Barrett EM, Bankhead CR, et al. The incidence of rheumatoid arthritis in the United Kingdom: results from the Norfolk Arthritis Register. Br J Rheumatol 1994;33:735-9
14. Kirwan JR, Reeback JS. Stanford Health Assessment Questionnaire modified to assess disability in British patients with rheumatoid arthritis. Br J Rheumatol 1986:25:206-9.

15. Thomson W, Harrison B, Ollier B, et al. Quantifying the exact role of HLA-DRB1 alleles in susceptibility to inflammatory polyarthritis: results from a large, population-based study. Arthritis Rheum 1999:42:757-62.

16. Wiles N, Symmons DP, Harrison B, et al. Estimating the incidence of rheumatoid arthritis: trying to hit a moving target? Arthritis Rheum 1999;42:1339-46.

17. Larsen A, Dale K, Eek M. Radiographic evaluation of rheumatoid arthritis and related conditions by standard reference films. Acta Radiol Diagn (Stockh) 1977;18:481-91.

18. Bukhari M. Harrison B, Lunt M, et al. Time to first occurrence of erosions in inflammatory polyarthritis: results from a prospective community-based study. Arthritis Rheum 2001;44:1248-53.

19. Ware JE Jr, Sherbourne CD. The MOS 36-item short-form health survey (SF-36). I. Conceptual framework and item selection. Med Care 1992;30:473-83.

20. Wiles NJ, Scott DG, Barrett EM, et al. Benchmarking: the five year outcome of rheumatoid arthritis assessed using a pain score, the Health Assessment Questionnaire, and the Short Form-36 (SF-36) in a community and a clinic based sample. Ann Rheum Dis 2001;60:956-61.

21. Robins JM, Hernán MA, Brumback B. Marginal structural models and causal inference in epidemiology. Epidemiology 2000;11:550-60.

22. van Buuren S, Boshuizen HC, Knook DL. Multiple imputation of missing blood pressure covariates in survival analysis. Stat Med 1999;18:681-94.

23. Pincus $\mathbf{T}$. The case for early intervention in rheumatoid arthritis. J Autoimmun 1992;5(Suppl A):209-26.

24. Ledingham J, Deighton C; British Society for Rheumatology Standards, Guidelines and Audit Working Group. Update on the British Society for Rheumatology guidelines for prescribing TNFalpha blockers in adults with rheumatoid arthritis (update of previous guidelines of April 2001). Rheumatology (Oxford) 2005; 44:157-63.

25. van der Heide A, Jacobs JW, Bijlsma JW, et al. The effectiveness of early treatment with "second-line" antirheumatic drugs. A randomized, controlled trial. Ann Intern Med 1996:124:699-707.

26. Verstappen SM, Jacobs JW, Bijlsma JW, et al. Five-year followup of rheumatoid arthritis patients after early treatment with disease-modifying antirheumatic drugs versus treatment according to the pyramid approach in the first year. Arthritis Rheum 2003;48:1797-807.

27. Aletaha D, Smolen JS. Effectiveness profiles and dose dependent retention of traditional disease modifying antirheumatic drugs for rheumatoid arthritis. An observational study. J Rheumatol 2002;29:1631-8.

28. De La Mata J, Blanco FJ, Gómez-Reino JJ. Survival analysis of disease modifying antirheumatic drugs in Spanish rheumatoid arthritis patients. Ann Rheum Dis 1995;54:881-5.

29. Wijnands MJ, van't Hof MA, van Leeuwen MA, et al. Long-term second-line treatment: a prospective drug survival study. Br J Rheumatol 1992;31: 253-8.

30. Aletaha D, Funovits J, Keystone EC, et al. Disease activity early in the course of treatment predicts response to therapy after one year in rheumatoid arthritis patients. Arthritis Rheum 2007:56:3226-35.

31. Rosenbaum PR, Rubin DB. The central role of the propensity score in observational studies for causal effects. Biometrika 1983;70:41-55.

32. Brookhart MA, Schneeweiss S, Rothman KJ, et al. Variable selection for propensity score models. Am J Epidemiol 2006;163:1149-56.

33. Rubin DB. Estimating causal effects from large data sets using propensity scores. Ann Intern Med 1997;127(8 Pt 2):757-63.

34. Robins JM, Mark SD, Newey WK. Estimating exposure effects by modelling the expectation of exposure conditional on confounders. Biometrics 1992:48:479-95 